\title{
Horticulture Information on the Internet: Cyberhorticulture on the Information Super Highway
}

\author{
David W. Burger ${ }^{1,3}$, J.B. Katcher', \\ Nathan E. Lange', Jose L. Saenz', \\ Scott P. Sherman', and Mark R. Stoutemyer'
}

Additional index works. World-Wide Web, electronic communication

Summary. Graduate students in horticulture at the Univ. of California, Davis, spent an academic quarter learning how to use the Internet and World-Wide Web (WWW) to access and collect information. The collected information was organized and placed on the WWW where it is available to anyone with access to the Internet.

\footnotetext{
$\mathrm{T}$
} he Internet offers enhanced communication among horticulturists and increases the availability of horticultural information on virtually any topic. Through the ages horticultural information and expertise have been passed from one individual to another in many ways. Early horticulturists shared their knowledge through personal conversations and demonstrations. Egyptian hieroglyphics, more than 3000 years old, depict planting, irrigating, fertilizing, and pruning techniques still in use today. Some of the earliest printed books focused on the production, storage, and distribution of foods. During the American postindustrial revolution of the late 1800s, newspapers and magazines were the principal media for communicating information between professional and amateur horticulturists. With the advent of professional societies, entire books dedicated solely to horticulture (e.g., proceedings) were printed to organize and distribute the evergrowing volume of new information on horticulture. Popular journals and magazines have developed into an important means for collecting and distributing horticultural information.

In the last 50 years, electronic media have increased steadily in importance. Radio and television have been effective communication tools. Since the 1970s, videotape and computer technologies have increased the flow of information to a global scale. Video cassette recorders now

'Department of Environmental Horticulture, University of California, Davis, CA 95616.

2Deparment of Pomology, University of California, Davis, CA 95616.

'To whom reprint requests should be addressed.

The cost of publishing this paper was defrayed in part by the payment of page charges Under postal regulations, this paper therefore must be hereby marked advertisement solely to indicate this fact. 
are ubiquitous in our society and provide an easy means of sharing high-quality graphics and video and audio narration.

Stand-alone and networked computers provide the additional advantage of very rapid access to huge reservoirs of knowledge. An even-greater power of computers and electronic communication is being realized as computer networks become more widespread and interconnected globally. The current global network, the Internet, has incredible potential for providing a means for rapid communication among people anywhere on, earth. None of these improvements in communication will replace the original sharing of knowledge from one person to another; however, they will facilitate more rapid and efficient means of communicating and accessing important horticultural information.

During the winter quarter 1995, horticulture graduate students at the Univ. of California, Davis, participated in a seminar focused on the future of horticulture. Various forms of electronic communication were explored intensively. The students had campus computer user accounts that facilitated easy electronic communications among themselves and the instructor. This was accomplished via electronic mail (email), a class newsgroup, and the Internet Relay Chat (IRC).

Email was used in the class for announcements, reminders, and personal communications throughout the quarter. A newsgroup was created to provide students with an efficient means of sharing newly acquired information and insights concerning Internet resources. Newsgroups differ from email in that information is not sent automatically to each user's account; rather, a user has to access the newsgroup electronically to read or post new information. This has the advantage of not allowing unsolicited email to appear in a user's mailbox, but it requires some discipline to check the newsgroup routinely to stay current. The IRC allows for two or more logged-on users to have real-time conversations via the keyboard at the same time (Cady and McGregor, 1995).

During one session of the quarter a virtual seminar was held using IRC in which professional horticulturists from around the country participated in an hour-long discussion of horticultural issues. Participants included an extension professional from North Carolina State Univ. and a landscape contractor from Oakland, Calif. The off-campus participants were located at their computers and the students were either stationed at on-campus computers or at home. One student characterized the hour as "... like having a conference call in slow motion."

Once the students were familiar and comfortable with the use of the Internet, they were exposed to additional useful tools for finding and retrieving information. These tools included Archie, anonymous file transfer protocol (FTP), Gopher and the World-Wide Web (WWW) (Cady and McGregor, 1995 ). Archie is an Internet tool used to find information based on keyword searches. Once a particular word or phrase is found, FTP can be used to retrieve the information of interest. Gopher is a protocol useful in retrieving text-based information stored on computers around the world.

All of these capabilities (Archie, FTP, and Gopher) are integrated into the WWW. The WWW is a wide-area hypermedia information retrieval initiative aimed at giving global access to a large collection of documents. Using a system of hypertext links, information can be found easily, retrieved and used by any individual with Internet access. The WWW greatly increases the ease and speed of accessing information on the Internet. Using WWW searching tools (e.g., WebCrawler, World-Wide Web Worm), students searched for horticultural topics from around the world. The topics and related links that were found have been organized and published in a hypertext markup language (HTML) document, Horticulture Information on the Internet (Lemay, 1995). This document is accessible via the Internet using a WWW browser (e.g., Mosaic, Netscape, MacWeb, WinWeb, Lynx) from anywhere in the world.

Fig. 1. Initial home page of Horticulture Information on the Internet. Its Uniform Resource Locator address is: http:// envhort.ucdavis.edu/horttech/hort.htm

\section{Horticulture Information on the Internet}

Mailing Lists

Gophers

World-Wide Web Sites
Newsgroups

FTP Sites

Email Your Comments/Suggestions 
The first screen (also known as the home page) of Horticulture Information on the Internet provides viewers (browsers) with a basic menu of selections (Fig. 1). These selections include mailing lists, Usenet newsgroups, Gophers, FTP sites, and World-Wide Web sites. Each selection leads to horticultural resources on the Internet. Mailing lists include interests in home gardens, Master Gardeners, and bromeliad or bonsai enthusiasts. The Usenet newsgroup section provides access to ongoing discussions on agroforestry, orchids, and roses among others. Gophers originating from university, government, and special topic sites (e.g., plant biology, irrigation) are included. The FTP sites provide sources of information on gardening software and archival information from various newsgroups (e.g., rec. gardens, bionet.plants). The largest and most complete section is the WWW sites section, which includes sites focused on home horticulture and gardening, university horticulture departments, specialty horticulture information (e.g., daylilies, orchids, carnivorous plants, grapevines), arboreta and botanical gardens (e.g., Kew, Missouri Botanic Garden), plant biology, integrated pest management, environmental sciences, general agriculture, irrigation information, and general topics. Links to WWW searching tools also are provided, as is the ability to send comments/replies via email to the originators of Horticulture Information on the Internet. This HTML document will be updated regularly as new electronic information on horticulture is found.
The gathering, organizing, and sharing of horticultural information in the future will depend on our ability to use modern communication systems. The WWW provides a rich environment for effective and exciting communication and multimedia presentation of horticultural information. It is unlikely this technology will completely replace printed information. Instead, a synergism may occur where tables of contents from books and journals are placed on the Internet to attract the attention of people on-line. Information that is relatively static (e.g., images used for plant or pest identification, horticultural technique descriptions, general cultural recommendations) will find a place on the WWW. In doing so, this information will be made available to a global audience. The WWW also maybe useful in providing a place to hold virtual meetings and virtual training sessions. In the near future the world community will not be hampered by the differences in time or distance. The global network will allow anyone, anywhere in the world, to reach almost anyone else.

\section{Literature Cited}

Cady, G.H. and P. McGregor. 1995. Mastering the Internet The definitive guide for business, home, government and educational use. Sybex, Inc., Alameda, Calif.

Lemay, L. 1995. Teach yourself web publishing with HTML in a week. SAMS Publishing, Indianapolis. 